\title{
HUMANISME I CRÍTICA EN T. S. ELIOT I CARLES RIBA
}

\author{
HUMANISM AND CRITICISM \\ IN T. S. ELIOT AND CARLES RIBA
}

\author{
JoRdi MALÉ \\ Universitat de Lleida \\ jordi.male@udl.cat
}

Resum: T. S. Eliot i Carles Riba són dos autors amb moltes similituds: tots dos van viure aproximadament durant la mateixa època (la primera meitat del segle $\mathrm{xx}$ ), tots dos van destacar com a poetes i com a crítics, i tots dos van escriure sobre temes literaris semblants, com, per exemple, l'humanisme, i sobre diversos autors de la literatura europea, com Dante, Goethe i Baudelaire. Però les seves diferents circumstàncies biogràfiques i els diferents contextos literaris, socials i polítics van condicionar la seva concepció de l'humanisme i la seva interpretació d'alguns dels principals escriptors de la cultura occidental. L'objectiu d'aquest article és fer un exercici de literatura comparada per relacionar i contrastar aquestes diferents concepcions i interpretacions d'Eliot i Riba.

Paraules clau: T. S. Eliot, Carles Riba, humanisme, crítica, literatura europea.

Abstract: T. S. Eliot and Carles Riba are two writers with many similarities: they both lived around the same time (the first half of the twentieth century), both stood out as poets and critics, and both wrote on similar literary topics, such as humanism, and several authors of European literature, like Dante, Goethe and Baudelaire. But their different biographical circumstances and their different literary, social, and political contexts conditioned their conception of humanism and their interpretation of some of the leading writers of Western culture. The aim of this paper is to do a comparative literature exercise to relate and contrast these different conceptions and interpretations of Eliot and Riba.

Key words: T. S. Eliot, Carles Riba, Humanism, Criticism, European literature. 
JoRdi MALÉ

Humanisme i critica en T. S. Eliot i Carles Riba

Si es comparen la vida i l'obra de T. S. Eliot (I888-1965) i Carles Riba (I893-I959), dos autors del tot coetanis, cal convenir que més aviat resulten divergents. Els distints contextos personals, literaris, socials i polítics dins els quals van produir els seus textos en van fer dos escriptors ben diferents. Ambdós foren poetes i crítics, certament. Però en la mateixa faceta creativa de la seva obra també es distingeixen, perquè l'autor nordamericà nacionalitzat anglès acabà decantant-se cap al teatre, mentre que el català, que en la joventut havia optat també per la narrativa, esmerçà gran part del seu temps, al llarg de tota la vida, en la traducció.

Quant a les respectives biografies, pocs punts de coincidència hi trobaríem. Eliot, graduat en Filosofia a Harvard (on també estudià matèries com Literatura Anglesa i Literatura Comparada), s'acabà de formar a França i preparà una tesi doctoral sobre la filosofia de F. H. Bradley, que no arribà a llegir. Des de 19ı4, d'altra banda, visqué a Anglaterra, coincidint amb l'inici de la Primera Guerra Mundial; l'any següent es casà amb Vivienne Haigh-Wood, amb qui mantingué una relació difícil, fins a separar-se'n el 1933; abans, el 1927, es nacionalitzà anglès. Tingué dues altres companyes: la primera, Mary Trevelyan, la conegué un any abans de l'esclat de la Segona Guerra Mundial, i amb la segona, Esmé Valerie Fletcher ( 38 anys més jove que ell), s'hi casà el $1957 \mathrm{i}$ hi visqué fins a la mort, sense deixar fills de cap de les dues esposes. ${ }^{1}$

Riba, per la seva banda, estudià les carreres de Dret i de Filosofia i Lletres a la Universitat de Barcelona i va fer els cursos de doctorat a Madrid, sense arribar a acabar una tesi sobre Safo (no serà fins als quaranta-quatre anys que assolirà el doctorat amb un estudi sobre Maragall). Es casà amb la poeta Clementina Arderiu el 1916, amb qui va conviure sempre feliçment, i tingueren quatre fills (un dels quals morí als sis anys). Amb residència a Barcelona, la seva ciutat natal, visqué la dictadura de Primo de Rivera, la proclamació de la república, l'esclat de la Guerra Civil i, entre 1939 i I943, l'exili a França, on també patí les conseqüències de la Segona Guerra Mundial. Retornat a Barcelona, hi passà els durs anys de la postguerra, durant la qual continuà escrivint alhora que maldà, com altres intel-lectuals, per mantenir viva la cultura i la llengua catalanes, llavors perseguides. ${ }^{2}$

És prou clar que les experiències vitals d'ambdós autors, amb les diferents circumstàncies sociopolítiques al llarg de més de mig segle d'existència, tenen pocs punts de coincidència, al marge de compartir un comú marc històric europeu. I el mateix pot dir-se quant als contextos literaris en què se situen les obres respectives. Si bé durant el període d'entreguerres van convergir arreu d'Europa, en dinàmiques i graus diver-

I. Quant a la vida d'Eliot, vegeu Worthen (2017).

2. Quant a la vida de Riba, vegeu Medina (1989). 
sos, tot de moviments i corrents literaris i artístics (que van des del classicisme fins a l'avantguarda), la realitat d'una literatura consolidada com l'anglesa (a Anglaterra i a l'Amèrica del Nord) no es pot comparar amb la de la catalana, que des de mitjan segle XIX i, més intensament, des del tombant del segle XX, vivia un procés de recuperació i construcció paral.lel al de la normalització de la seva llengua; un procés, a més, interromput en acabar la Guerra Civil i que la dictadura franquista va intentar avortar.

Quant a la poesia d'Eliot i de Riba, no són facils de comparar atesa la disparitat tant en els temes predominants com en les formes de què se serviren. Sembla més factible, en canvi, contrastar la producció crítica respectiva, estretament vinculada amb l'ideari sobre la literatura de cadascun. Van compartir, per exemple, alguns recursos i procediments, com ara el de criticar les obres d'altres poetes per reivindicar la concepció pròpia de la poesia, especialment en els seus primers articles; així ho admetia Eliot (1985: I6): "In my earlier criticism, both in my general affirmations about poetry and in writing about authors who had influenced me, I was implicitly defending the sort of poetry that I and my friends wrote». Riba, semblantment, va articular diversos dels seus primers articles mitjançant dicotomies, un dels termes de les quals era l'obra criticada i l'altre, malgrat que no ho explicités, la poètica pròpia.

Com a crítics amb plena consciència de la seva tasca, tots dos partien d'unes determinades idees sobre el fet literari, especialment sobre la poesia, que anirien evolucionant en paral.lel amb la seva obra i la seva vida; però aquestes idees, malgrat algunes coincidències, diferien en molts aspectes. Les produccions crítiques d'ambdós autors, a més, es distancien tenint en compte que la de Riba versa principalment sobre les lletres catalanes, mentre que en Eliot predominen els textos dedicats a la literatura en llengua anglesa. Ara: el fet de compartir una mateixa tradició cultural i literària, la d'Europa, propicià que ambdós autors tractessin, en alguns articles i assaigs de mena diversa, d'uns mateixos temes: des de l'humanisme fins a autors com Baudelaire, Dante i Goethe.

L'objectiu del present text és fer un exercici de literatura comparada tot contrastant diversos escrits crítics que Eliot i Riba van dedicar a tres dels principals autors del cànon occidental i al mateix concepte de l'humanisme, per aprofundir, així, en el seu ideari literari i humanístic.

\section{HUMANISME}

Tres articles d'Eliot contenen el mot humanisme dins el títol: «The Humanism of Irving Babbitt» (I928), "Second Thoughts about Humanism» (I929) i «Religion 
JoRdi MALÉ

Humanisme i critica en T. S. Eliot i Carles Riba

without Humanism» (I930). ${ }^{3}$ En el cas de Riba, en són dos: «Humanisme i poesia» (I932) i "L'humanisme a Catalunya» (I940). ${ }^{4}$ Tot i que ambdós crítics també es van ocupar d'aquest concepte en altres textos, en van fer el tema central dels cinc esmentats. Però l'un i l'altre el van tractar de manera ben diferent, per no dir pràcticament oposada: d'una banda, perquè els textos de Riba volen ser una exposició d'una part de les seves idees sobre l'humanisme, mentre que els d'Eliot expressen sobretot una crítica a una determinada concepció humanística; i, d'altra banda, perquè són ben diferents els contextos de les respectives reflexions.

Que el primer dels tres articles d'Eliot aparegués en una revista dels Estats Units, quan ja feia més d'una dècada que el poeta dels Quatre quartets s'havia establert a Anglaterra, no és casual. El dedicava a Irving Babbitt, el crític nord-americà que fou professor seu a Harvard i que tanta influència va tenir sobre ell (Margolis 1972: 4-9). Babbitt, amb Paul Elmer More, havia impulsat, al tombant del segle xx, el corrent de pensament que seria conegut com New Humanism, les idees del qual van ser recuperades entre el final dels anys vint i l'inici dels trenta i esdevingueren objecte de polèmica, amb la participació dels mateixos promotors del corrent, en revistes americanes com Forum o The Bookman, i també en alguna d'europea, com ara Criterion, dirigida per Eliot mateix.

L'humanisme propugnat per Irving Babbitt tenia com a objectiu últim formar «the complete man", això és: "the old humanist ideal of the perfection of human life to be achieved by a proportionate and harmonious development of every part of human nature» (Diehl I947: 30; veg. Babbitt 1908). Aquest anhel de perfectibilitat el duia a insistir «upon the importance of reason, restraint, discipline, proportion, and law»; uns principis la millor expressió dels quals era trobada en els clàssics (Margolis I972: 7).

3. El primer va aparèixer pel juliol de 1928 en la revista nord-americana Forum i va ser publicat en volum dins For Lancelot Andrewes (1928), i posteriorment inclòs dins l'edició de 1950 de Selected Essays; també hi va ser inclòs el segon, una ressenya abans publicada dins el número de juny-agost de i929 de la revista anglesa The New Adelphi; el tercer va ser escrit per al volum col-lectiu Humanism and America (1930).

4. Són els textos de dues conferències que Riba mai no va arribar a publicar però de les quals ens han arribat diversos testimonis. La primera va ser pronunciada a l'Ateneu de Girona el 22 de març de $1932 \mathrm{amb}$ motiu del centenari de Goethe; se'n conserva un guió manuscrit i la transcripció del parlament, que sembla força completa, publicada pel diari La Publicitat el 3I de març, la qual va ser recuperada per Enric Sullà a Faig, 23-24, 1985, p. 173-177 (Riba 1988: I25-I29); cal tenir present, però, que no tenim la certesa que Riba revisés aquesta transcripció. La segona conferència és una de les diverses que el poeta i crític va preparar, després de la derrota republicana a la Guerra Civil, per difondre i fer conèixer a l'estranger els valors de la llengua i la literatura catalanes; se'n conserven els manuscrits i els mecanoscrits tant de l'original català com d'una versió castellana (consultables al Corpus Literari Digital de la Càtedra Màrius Torres); la catalana va ser transcrita per Segimon Serrallonga a Reduccions, 23-24, 1984, p. 23-43 (Riba 1988: I68-I87). 
Amb aquesta concepció de l'humanisme — reduïda als seus termes essencials—, Eliot podia avenir-s'hi perfectament. De fet, són diversos els textos seus dels anys vint en què mostra la seva admiració pel qui fou el seu mestre tot lloant-ne o recomanant-ne les obres (Margolis 1972: II2). Fins que, cap a 1927, tots dos es van retrobar casualment. És probable que aquesta trobada fos l'origen del primer dels seus articles sobre el tema de l'humanisme, que està escrit des d'una perspectiva molt concreta arran d'un canvi decisiu en la seva vida. El mateix Eliot («To Criticize the Critic», I96I; Eliot 1985: I5) n'ha deixat testimoni:

My old teacher and master, Irving Babbitt, to whom I owe so much, stopped in London on his way back to Harvard from Paris, where he had been lecturing, and he and Mrs. Babbitt dined with me. I had not seen Babbitt for some years, and I felt obliged to acquaint him with a fact as yet unknown to my small circle of readers (for this was I think in the year 1927) that I had recently been baptized and confirmed into the Church of England.

Babbitt, continua explicant Eliot, el va impulsar a fer pública la seva conversió religiosa. I això va motivar la coneguda autodefinició que va incloure al prefaci del que seria el seu aplec d'articles següent, For Lancelot Andrewes (1928): "classicist in literature, royalist in politics, and anglo-catholic in religion» (Eliot 1970: 7).

La conversió a l'anglicanisme d'Eliot (que havia estat educat en l'unitarisme cristià [Margolis 1972: $16 \mathrm{n}$.]) va condicionar tant la seva vida com la seva obra. Especialment la seva producció assagística i crítica. Això explica que el tema principal del seu article sobre l'humanisme de Babbitt (i també el dels altres dos) sigui la relació entre humanisme i religió.

Eliot pren com a referència la darrera de les obres fins llavors publicada pel seu mestre, Democracy and Leadership (1924), i posa en qüestió la doctrina de l'humanisme que conté. Parteix del postulat que «the problem of humanism is undoubtedly related to the problem of religion», i constata que, tanmateix, Babbitt, al llarg del llibre, «is unable to take the religious view - that is to say that he cannot accept any dogma or revelation»; dit altrament: per a aquest professor de Harvard, «humanism is the alternative to religion» («The Humanism of Irving Babbit», 1928; Eliot 1986: 472). L'aprofundiment en les conviccions religioses d'Eliot arran de la seva recent conversió el feien discrepar obertament d'aquesta darrera proposició, perquè, en tant que fets històrics, «humanism has been sporadic, but Christianity continuous» (Eliot 1986:473). La superioritat, als seus ulls, de la religió cristiana, el duia a formular una definició més aviat negativa de l'humanisme: «Humanism is, I think, merely the state of mind of a few persons in a few places at a few times. To exist at all, it is dependent upon 
JoRdi MALÉ

some other attitude, for it is essentially critical — I would even say parasitical» (Eliot 1986: 473). Aquest últim adjectiu cal entendre'l en funció de la conclusió a què arriba al final de l'article: «The humanistic point of view is auxiliary to and dependent upon the religious point of view» (1986: 480). $\mathrm{O}$, com dirà al següent article: «Humanism is insufficient without religion» («Second Thoughts about Humanism», 1929; Eliot 1986: 482).

És des d'aquest axioma que Eliot ressegueix i qüestiona alguns dels principis de l'humanisme de Babbitt, com ara l'anhel de civilització: bo i comptant que per civilització el seu mestre entenia no pas «material progress, cleanliness, etc.», sinó «a spiritual and intellectual coordination to a high level», Eliot sentencia que «is doubtful whether civilization can endure without religion, and religion without a church» (1986: 479). Una afirmació sols sostenible per qui havia passat a fonamentar la seva vida en la fe cristiana —en contrast amb Babbitt, que no en professava cap, de religió. ${ }^{5}$

Els altres dos articles que el crític anglès va dedicar a l'humanisme van en la mateixa línia. El segon és, de fet, la ressenya d'una obra d'un dels deixebles de Babbitt: American Criticism, de Norman Foerster (Boston, Houghton Mifflin, 1928). En tant que deixeble, els plantejaments de Foerster resulten semblants als del crític de Harvard i, consegüentment, són també discutits per Eliot. Com ara que «there is a "pure Humanism" which is incompatible with religious faith» i que la distinció entre religió $i$ humanisme es palesa en el fet que "Humanism 'holds that the value of supernatural must be tested by the intellect'”, això és: no per la fe sinó per la raó (Eliot 1986: 484). La qüestió de la transcendència ("the supernatural») és fonamental per a Eliot, i la seva rèplica a aquelles idees resulta contundent: «If you remove from the word "human" all that the belief in the supernatural has given to man, you can view him finally as no more than an extremely clever, adaptable, and mischievous little animal» («Second Thoughts about Humanism»,1929; Eliot 1986: 485).

En el tercer article, «Religion Without Humanism», tot i afirmar-hi ja d'entrada que «humanism is in the end futile without religion» (Eliot 1930: 105), si més no defensa que la religió, com també la filosofia o la ciència, «depend upon humanism to preserve their sanity»; i vincula l'humanisme amb «the full realisation and balance of the disciplined intellectual and emotional life of man» (Eliot I930: III). ${ }^{6}$

5. En mots d'Eliot mateix: «[Babbitt] knows too many religions and philosophies, has assimilated their spirit too thoroughly [...] to be able to give himself to any. The result is humanism"; un humanisme que no podia, doncs, compartir (Eliot 1986: 480).

6. Eliot no arriba a concretar cap definició del concepte d'humanisme, com ell mateix admet al final d'aquest article (1930: II2). 
En contrast amb Eliot, el tema de la relació entre humanisme i religió no va interessar Carles Riba. Només s'hi refereix al principi de la conferència «Humanisme i poesia» (I932), i ho fa des d'una perspectiva històrica, en resseguir els inicis de la tradició humanística i exposar les dificultats dels autors del Renaixement per conciliar l'interès per l'antiguitat clàssica amb el cristianisme.

Tot i que pot afirmar-se que Riba va professar sempre el catolicisme, no va ser fins a la postguerra que va afrontar amb plena consciència les seves creences religioses i va aprofundir-hi; ${ }^{7}$ la seva fe assumida des d'aleshores va influir, certament, la seva poesia i la seva crítica, però sense arribar al dogmatisme que respira la d'Eliot.

Quan Riba parlarà d'humanisme durant els anys trenta, d'altra banda, no tindrà com a referència el New Humanism americà, sinó el que s'ha convingut a designar com a "Tercer Humanisme», corrent d'interès pels clàssics propugnat des de mitjan anys vint a la revista alemanya Die Antike per Werner Jaeger (fundador de la revista i futur autor de la famosa Paideia, obra sobre els ideals educatius i formatius de la cultura grega); un corrent que — per dir-ho sintèticament amb l'historiador italià Massimiliano Pavan (I977: 342) — "prospettava una rinascita del classico attraverso la mediazione tra la filologia "scientifica" del maestro Wilamowitz e l'idealismo dei "letterati"». ${ }^{8}$

Enfront de la naturalesa fonamentalment filosòfica del New Humanism angloamericà, el «Tercer Humanisme» tenia també una dimensió filològica; i els clàssics en són no pas una referència exemplaritzant sinó el mateix fonament. Els clàssics grecollatins, essencialment, i bo i comptant que l'origen del pensament humanístic era situat a la Grècia antiga.

Riba degué descobrir les idees de Jaeger durant la seva estada a Alemanya l'any I922 per a estudiar amb el seu mestre Karl Vossler, perquè entre les separates de textos filològics que va endur-se'n (la majoria de Vossler) hi ha la de la conferència de Jaeger titulada Humanismus und Jugendbildung (Humanisme i formació de la joventut). ${ }^{9}$ Una conferència que començava amb aquesta declaració: "L'humanisme és present arreu on l'Antiguitat és sentida com una gran força viva i com un poder educatiu autònom» (Jaeger I92I: 5). ${ }^{10}$

7. Fins llavors, el catolicisme de Riba fa tot l'efecte que era «cultural», fruit de l'educació i l'ambient predominantment religiós que es vivia a la Catalunya del principi del segle xx. La seva esposa Clementina Arderiu, en canvi, sí que ja de ben jove va tenir un profund sentiment cristià, com mostren les seves primeres obres poètiques.

8. Vegeu Miralles (2007: 69-75, I64-170 i 313-319); i també Malé (2001: 91-94, d'on extrec alguns passatges).

9. Berlin, Weidmannsche Buchhandlung, I92I.

Io. Agraeixo a Ignasi Vila la traducció de les citacions alemanyes. 
JoRdi MALÉ

Humanisme i critica en T. S. Eliot i Carles Riba

Si bé el tema central de la conferència és l'ensenyament dels clàssics als estudiants d'institut (Gymnasium), en les primeres pàgines Jaeger esbossa moltes de les idees claus de la seva concepció de l'humanisme i del món clàssic. D’una banda, vincula la perdurabilitat dels humanistes a la força de la influència grega en totes les èpoques i, principalment, a la del seu ideal educatiu i de formació — un ideal que vol deixar enrere el simple gaudi de bellesa estètica amb què sovint s'identificava l'antiguitat clàssica. Aquest ideal educatiu dels grecs s'encamina, no cap a formar l'home amb vista a un ofici, sinó a educar l'home per realitzar-se plenament com a tal; i amb aquest fi eren posades al seu servei totes les obres de cultura: des d'Homer fins als tràgics, els poetes i els músics, les disciplines de la paraula i del pensament, etc. Jaeger veu, així, l'humanisme com «el camí cap a l'home», segons que va ser assenyalat pels grecs (Jaeger 1921: I3).

Un humanisme, doncs, que s'identifica amb la paideia grega ( $\left.\pi \alpha 1 \delta \varepsilon^{\prime} \alpha\right)$, paraula «amb la qual [a l'antiga Grècia] designaven la totalitat de la seva cultura espiritual», i que «ens porta de forma clara al coneixement que, per al seu pensament, la cultura i l’educació són la mateixa cosa» (Jaeger I92I: IO). ${ }^{11}$

Que aquesta serà la concepció de l'humanisme del Riba dels anys vint i trenta ho prova el primer i més important dels textos que va dedicar a aquesta qüestió, «Humanisme i poesia» (1932), que s'inicia amb una indubtable referència a l'ideal de la paideia: «En l'Humanisme, a través de les seves diverses interpretacions, trobem una idea sempre present: la idea de l'Antiguitat com a força i principi educador, l'Antiguitat com a "situadora de l'home"» (Riba I988: 125).

Els dos conceptes clau són, doncs, l'home i l'antiguitat. O, més precisament, els textos de l'antiguitat clàssica, atesa la dimensió filològica d'aquesta concepció de l'humanisme. Una dimensió que tindrà una traducció pràctica en la creació de la Fundació Bernat Metge el 1922, gràcies al mecenatge de Francesc Cambó, amb l'objectiu de publicar versions catalanes dels autors clàssics grecollatins. Riba n'esdevindrà un dels puntals — no sols com a traductor, sinó també com a professor al període d'entreguerres. I també hi tingueren un paper destacat Joan Crexells i Lluís Nicolau d'Olwer, dos altres humanistes catalans que compartien l'ideari humanístic de Riba (veg. Malé 200I: 94-IO2).

Nicolau d'Olwer, per cert, s'apropava a la concepció més filosòfica de l'humanisme d'Eliot en un breu text de 1933, en què afirmava que «l'humanisme no és pas

II. Vegeu també l'apartat introductori de la seva obra magna, Paideia, de 1936 (Jaeger 1988: 3-16, esp. 6 i I2). Riba llegirà aquesta obra com a molt aviat cap al final de la Guerra Civil i la utilitzarà l'any 1950 per redactar la «Introducció» al primer volum de la seva traducció de les Tragèdies de Sòfocles a la Fundació Bernat Metge. 
un cos de doctrina», en el sentit que "no és una religió $[\ldots]$ ni una ciència $[\ldots]$ ni un partit», i el fonamentava, tot assimilant-lo al liberalisme, en «la idea que [...] en allò que és essencial els homes són i han estat iguals» (Nicolau I933: I). Eliot, paral.lelament, remarcava que no era funció de l'humanisme «to provide dogmas», i que «it operates against fanatism» (Eliot 1986: 488). ${ }^{12}$ Però si per al crític anglès el fonament de l'actitud humanística era la "cultura» («it is general culture»), el català posava èmfasi en la idea de «la projecció de l'home», i sintetitzava la seva concepció de l'humanisme amb la fórmula del dramaturg grec Menandre (al qual va dedicar la seva tesi doctoral): «sóc home i res d'humà no m’és estrany» (I933: I). Aquesta mateixa fórmula, en la versió llatina de Terenci, és la que havia emprat Riba un any abans (I932) per cloure la seva conferència «Humanisme i poesia» (Riba I988: I29):

\footnotetext{
Aleshores l'Antiguitat no és closa, sinó que continua vivint com a força operant i contenint en si un dels principis vitals que l'home modern s'ha apropiat amb més d'entusiasme: aquell que podria simbolitzar-se en els dos versos immortals de Terenci: «sóc home i res del que és humà m'és aliè», i "que és graciós l'home quan és home!»
}

Aquesta conferència, com el seu títol indica, vol posar en relació l'humanisme amb la poesia, en consonància amb la dimensió filològica — ara en el sentit etimològic de l'adjectiu - que Riba donava al primer concepte. Es tracta, doncs, d'enfocar-lo des d'una perspectiva literària, bo i considerant la poesia com una manifestació de l'humanisme. Una determinada poesia, és clar: ${ }^{13}$ la que té com a referència l'antiguitat clàssica en la forma i/o en el fons (o contingut) — no necessàriament en tots dos components alhora. Quant al fons, Riba pren com a model Goethe — a qui dedica bona part de la conferència. El situa dins l'evolució de l'humanisme des del Renaixement, quan sorgeix «una actitud d'interès per l'home considerat per si mateix» (Riba I988: I25). Aquesta actitud topa amb diversos obstacles al llarg dels segles, un dels quals fou el de la conciliació amb el cristianisme — com apuntava més amunt. Fins que Goethe deixa de sentir «l'oposició de les dues naturaleses, l'espiritual i la material», i «retorna envers l'Antiguitat en la posició que més fecunda ha semblat a l'home modern: l'Antiguitat en quant planteja problemes essencials a la Humanitat i, particularment, el problema del destí» (Riba I988: 126).

I2. «Second Thoughts about Humanism» (1929). Cal dir que el conservadorisme d'Eliot el feia reticent al liberalisme, si més no en religió.

13. El mateix pot dir-se de la novel-la: Riba considerava que un determinat tipus de novel-la, fonamentat en l'interès i l'amor per l'home, era representatiu de l'humanisme. Remeto al que ja vaig exposar a Malé (200I: I45-I56). 
JoRdi MALÉ

Humanisme i critica en T. S. Eliot i Carles Riba

Afrontar aquest problema del destí implica una consciència plena, això és: «[l’home] vol comprendre tota la vida, i més que comprendre-la, viure-la, però amb una consciència sempre alerta» (Riba 1988: I29). En l'extrem oposat a la poesia de Goethe, hi trobaríem el surrealisme, que justament renuncia al control de la intel-ligència i la consciència. Davant aquesta «bifurcació de la Poesia» (Riba 1988: 127), Riba opta per l'opció goethiana, perquè és la que s'adiu amb la seva pròpia poesia i la que identifica amb la tradició antiga de l'humanisme.

Si Goethe és la referència quant al fons de la poesia vinculada amb l'humanisme, Paul Valéry ho és respecte a la forma: «Esperit profundament clàssic, [Valéry] ha pres dels antics el sentit de la perfecció formal» (Riba I988: I28). No és casual que Riba el triii aleshores, a principis dels anys trenta, quan estava escrivint els sonets de Tres suites (datats entre 1930 i 1935), que aspiraven a una perfecció formal semblant a la del poeta francès.

Però el que interessa, sobretot, és la idea, de nissaga clàssica, del «sentit de la forma", perquè serà un dels eixos sobre el qual articularà la seva conferència de 1940 «L'humanisme a Catalunya». Una conferència escrita a l'exili després de la desfeta de la Guerra Civil, amb la qual, juntament amb altres textos i parlaments de tema semblant, Riba pretenia difondre i reivindicar la tradició i el valor de la cultura i la literatura catalanes a un públic estranger.

El seu punt de partença: establir que als països mediterranis «el principi educatiu clàssic és sempre en vetlla», en el sentit de romandre "disponible», i que es manifesta sobretot en el «sentit de la forma»; per llavors preguntar-se: «Existeix un sentit de la forma genèricament clàssic i específicament català?» (Riba 1988: I68-169). Per respondre-hi, Riba ressegueix la història catalana des de l'arribada dels grecs i en destaca els fets relacionats amb el món clàssic, per centrar-se, després, en la literatura i destacar els autors vinculables amb el classicisme, tant per la forma com, per exemple, per l'expressió «d'aquella pietas envers les coses, tan clàssica» (Riba 1988: I8I). ${ }^{14}$

En darrer terme, l'objectiu que perseguia Riba en voler destacar el «ferment humanístic» (I988: 185) al llarg de la història de la cultura catalana era de presentar aquesta a l'estranger, en uns moments que corria perill de desaparèixer per la repressió franquista, com una més dins el conjunt de la "cultura occidental» (1988: 187) i, doncs, dins «Europa en la seva voluntat de mantenir-se com a principi i unitat de civilitza-

I4. Ja ho havia fet en un text una mica anterior (1939): «Sobre l'acció del classicisme en la renaixença literària catalana» (Riba I988: I40-I5I). Sobre tots aquests textos dels anys I939-I940 i la seva relació amb la concepció ribiana de l'humanisme, remeto al que vaig exposar a Malé (2003). 
ció» (I988: I80), però destacant-ne el que té de singular (I988: I70-I7I), atribuïble a la manera particular en què s'hi manifesta el "principi humanístic clàssic» (I988: I4I):

En totes les manifestacions de l'esperit català, certs fets són constants i característics: el gust de la relació amb els homes i les idees, la potència assimilativa, la curiositat apassionada, però no per això menys crítica, la tendència naturalista, el sentit de la mesura, la complaença en les formes simples i austeres, l'aptitud normativa, l'amor de la llibertat, la preocupació pedagògica. Aquests fets, el mot humanisme els cobreix perfectament.

Algunes d'aquestes qualitats amb què Riba caracteritza l'esperit català dins la seva concepció de l'humanisme eren apreciades per Eliot, com el sentit de la mesura o la preocupació pedagògica. I si en alguna cosa coincidien ambdós crítics era en la importància de la cultura i de la tradició europees, amb les seves arrels clàssiques, com a fonament de la literatura pròpia. En un text no gaire distant en el temps de la conferència de Riba, Eliot defensava la necessitat de donar "a classical education», en referència a l'ensenyament dels clàssics grecollatins; i afirmava (I985: 150): ${ }^{15}$

This common basis of education has, I believe, had a great part in giving English letters of the past that unity which gives us the right to say that we have not only produced a succession of great writers, but a literature, and a literature which is a distinguished part of a recognizable entity called European Literature.

Tots dos crítics tenen com a referència, doncs, la literatura europea. I tots dos van dedicar textos a alguns dels seus principals autors. Uns textos en què, tanmateix, es posa de manifest la diferència entre els respectius idearis literaris i humanístics.

\section{BAUDELAIRE}

Riba va escriure un breu article sobre l'autor de Les fleurs du mal amb motiu del centenari del seu naixement el I92I («Baudelaire», dins Els Marges, I927; Riba I985: 232-235). Eliot, per la seva banda, li’n dedicà un de més extens (en tres parts) arran de la publicació d'una traducció anglesa dels Journaux intimes del poeta francès el 1930. ${ }^{16}$

15. "The Classics and the Man of Letters» (1942); ja s'hi referia el I9I9 a "Tradition and Individual Talent» (Eliot I986: I4-I5).

I6. «Baudelaire», dins Selected Essays (195133) (Eliot I986: 419-430). La referència de la traducció és: Charles Baudelaire, Intimate Journals, trad. de Ch. Isherwood, London, Blackmore Press, I930. Val a dir que Eliot ja havia dedicat almenys un altre text al poeta francès: «Baudelaire In Our Time» (dins For Lancelot Andrewes, 1928), escrit arran de la publicació d'una altra traducció: Charles Baudelaire, Prose and Poetry, trad. d'A. Symons, New

Caplletra 70 (Primavera, 2021), p. 139-167 
JoRdi MALÉ

Humanisme i critica en T. S. Eliot i Carles Riba

Són curioses les coincidències entre ambdós articles: l'un i l'altre s'ocupen no tant de la poesia com de la vida del poeta, de les seves idees i conviccions - i per això fan referència als seus Diaris intims (que és la motivació primera del text d'Eliot)—; en tots dos apareixen conceptes com ara el de la sinceritat i en ambdós són esmentats, al costat de Baudelaire, Dante i Goethe. Però per raons diferents.

Riba intenta esbossar esquemàticament l'evolució, en escriptors de la literatura europea d'ençà del segle xiII, del que seria una "trajectòria d'anhel» (Riba I985: 233). Una trajectòria que s'iniciaria en Dante, amb el seu camí d'ascensió, representat a la Divina Comèdia, des l'Infern al cim del Paradís, per arribar fins a la unitat de "tot l'escible, tota la cultura i tota la història», ${ }^{17}$ això és, fins a la contemplació de l'Absolut, de Déu. Però aquest anhel de contemplar l'Absolut, on hi ha la unitat de tot el saber, esdevindrà un amarg desengany per a Faust, perquè «la contemplació ve que s'exhaureix en ella mateixa» (Riba 1985: 233). I per això «Faust fuig de la ciència i torna, àvid de llum, en aquella mateixa vida de l'acció des de la qual Dant s'enfilava amunt amb impuls sostingut per la fe» (1985: 233). ${ }^{18}$

Aleshores Riba es pregunta si Baudelaire no representaria un segon desengany, «l'irreparable desengany de Faust»: com si «la trajectòria s'hagués continuat més avall de la realitat de l'acció; com si feta l'experiència, delejada per Faust, dels extrems del mal i del bé, a la fi hagués fet sotsobre amb la humanitat» (1985: 233). La conseqüència seria, aleshores, que «ja només la solitud torna a ésser possible: Baudelaire, des del fons d'un pou, mira els estels». A partir d'aquest punt, l'article intenta de reconstruir l'estat d'esperit de Baudelaire, en "la seva exacerbada sinceritat», tot relacionant-lo amb diversos aspectes de la seva obra i la seva persona, com ara el tedi, el dandisme, la imatgeria de la seva poesia i també la seva imaginació, a través de la qual el poeta maleït va arribar a creure que podria «sortir del pou» (1985: 234). Els Journaux intimes mostren, tanmateix — com apunta l'autor d'Els marges—, que a l'últim «aquesta illusió s'havia esvaït» i «revelen l'estrebar cansat per recomençar de cap i de nou la vida perduda», bo i lliurant-se al "treball continuat i ordenat segons els deures de cada dia», incloent-hi «el seu jurament d'oració quotidiana a Déu» (I985: 234-235).

La relació que Eliot plantejava entre Dante, Goethe i Baudelaire va per una altra via i és més circumstancial. Parteix del qualificatiu de «fragmentary Dante» que

York, Albert \& Charles Boni, I926; l'objectiu d'aquest article, però, era sobretot criticar severament la traducció de Symons i el pròleg amb què l'encapçalava.

17. Aquest passatge és una citació dins l'article, de la qual Riba no indica la font. Els mots pertanyen a la Storia della letteratura italiana de Francesco de Sanctis, dins el capítol dedicat a Dante i la Commedia (I958: 282); «escible» és un cultisme amb què Riba tradueix la forma italiana scibile 'saber o coneixement'.

I8. Riba segueix aquí De Sanctis, que és qui estableix la relació entre Dante i Goethe (1958: I78-I79). 
s'havia aplicat al poeta de Les fleurs $d u$ mal, i, sense negar-lo, en troba un altre de més adequat: «a later and more limited Goethe»(Eliot I986: 420). Perquè, si bé l'autor alemany era vist com «the symbol of perfect 'health' in every sense, as well as of universal curiosity», i el francès, en canvi, com «the symbol of morbidity in mind and concentrated interests in work» (1986: 420-42I), ambdós autors resulten equiparables en el fet que cadascun d'ells tenia «a sense of his own age», i així es reflecteix en els seus textos en prosa, com ara els Diaris intims. ${ }^{19}$

Aquestes reflexions inicials, tanmateix, són més aviat un pretext per abordar el tema que sobretot interessa a Eliot: procurar aclarir la relació de Baudelaire amb el cristianisme. No debades l'article està escrit després que el crític es convertís a l'anglicanisme, conversió que es va traduir en «his keener concern for moral and religious issues» $\mathrm{i}$, com a conseqüència, en la pràctica de complementar alguns dels seus articles sobre escriptors "with at least some reference to the religious significance of their work» (Margolis 1972: I08).

És aquí on divergeixen els interessos i les consideracions de Riba i Eliot. L'autor d'Els marges, apropant-se al mètode de la crítica estilística après amb Karl Vossler, ha mirat de trobar, en la personalitat de Baudelaire, alguns trets o principis de tipus psicològic que expliquin i donin sentit a aspectes de la seva obra, especialment de la poesia: el seu sentiment de solitud, d'isolar-se amb les concepcions de la seva ment, justificaria la presència sovintejada d'abstraccions als poemes; el fet d'haver de limitar-se a contemplar la vida, tancat dins el pou, i de veure-la, així, per sota, "on és més material, més de fang, més moridora», s'hauria traduït en una imatgeria poètica la plasticitat de la qual «és alguna cosa d'humà, massa humà, una magnífica tortura de veritat»; el seu elegant dandisme, finalment, com «una llei interior d'orgull heroic i fred» que li va fer creure en la possibilitat de sortir del pou, d'assolir "una més alta llibertat», hauria esperonat la seva imaginació a concebre "perspectives exòtiques» $\mathrm{i}$ "paradisos de plaers furtius» a través d' "un record viatger, un perfum, una melodia, una droga», motius que poblen, entre altres, Les fleurs du mal (Riba 1985: 234).

Eliot també duu a terme una certa indagació psicològica, però amb un altre objectiu. Parteix del debat entre els qui veien Baudelaire més a prop del satanisme i els qui l'apropaven al cristianisme, i es proposa de defensar que el poeta francès «is essentially Christian» (1986: 42I). Per això li interessen més els Journaux intimes que no pas Les fleurs du mal. De fet, els poemes baudelairians sembla que li facin més nosa que servei: hi troba massa «romantic detritus» (Eliot 1986: 423), especialment en les

19. Eliot reprendrà i desenvoluparà aquest tema respecte a Goethe a l'assaig «Goethe as the Sage» (dins On Poetry and Poets, 1957). 
imatges $;{ }^{20} \mathrm{i}$ confessa que «is not quite easy to conclude» per què aquesta poesia s'ha preservat, en contrast amb la d'altres poetes francesos coetanis, i ha esdevingut tan llegida arreu (1986: 425).

Al final, hi troba dues explicacions. D'una banda, per un aspecte formal: Baudelaire va aconseguir crear un nou llenguatge poètic connectat amb la vida contemporània i urbana, la imatgeria del qual és elevada "to the first intensity» (1986: 426) —un llenguatge que va influenciar la pròpia poesia d'Eliot. ${ }^{21}$

D'altra banda, la seva perdurabilitat com a poeta s'explica pel fet d'haver esdevingut «a reminder of the duty, the consecrated task, of sincerity» (1986:426). Sorprèn que el crític anglès empri un concepte característic de la crítica romàntica com és el de la sinceritat, difícil d'argumentar (cf. Wellek I988: 3II-3I2). Però és que, a partir d'aquí, ja sembla estar pensant essencialment en els diaris del poeta, el títol d'un dels quals remet a aquest concepte: Mon coeur mis à $n u$. Segons Eliot, malgrat que Baudelaire empra, en la seva obra, la mateixa parafernàlia que altres escriptors relacionats amb el satanisme, en ell significa «something else» — cal deduir que pel fet d'implicar-s'hi sincerament-: «But actually Baudelaire is concerned, not with demons, black masses, and romantic blasphemy, but with the real problem of good and evil». Més encara: «Baudelaire perceived that what really matters is Sin and Redemption» (1986: 427). I ho pot afirmar perquè, a Mon cour mis à nu, el mateix poeta francès havia proclamat, tot planyent-se'n, que la «vraie civilisation» no es troba «dans le gaz, ni dans la vapeur, ni dans les tables tournantes, elle est dans la diminution des traces du péché originel» (Baudelaire 1975: 697).2.

Eliot duu Baudelaire, així, cap a l'àmbit de la religió, per intentar mostrar que, al dessota dels elements de la seva obra vinculats amb el satanisme, hi ha una mentalitat autènticament cristiana, malgrat que no arribés a ser un bon cristià. Perquè «his business was not to practise Christianity, but — what was much more important for his time- to assert its necessity" (1986: 422). I aquesta comesa no la contradeia la seva condició de poeta maleit i damnat, perquè «damnation itself is an immediate form of salvation — of salvation from the ennui of modern life, because it at last gives some significance to living». La conclusió és, doncs, que «it is [...] really Sin in the permanent Christian sense, that occupies the mind of Baudelaire» (1986: 427).

20. Cal tenir present l'oposició d'Eliot al Romanticisme, tant en l'àmbit de la literatura com en el del pensament; veg. Margolis (1972: 25-25, $42-45$ i 52-68).

2I. Si no indico el contrari, la cursiva sempre és de l'original. Eliot desenvoluparà una mica més aquesta idea del llenguatge baudelairià, i la influència que va tenir sobre la seva pròpia poesia, en una digressió dins l'assaig «What Dante means to me» de I950 (Eliot 1985: I26-I27).

22. Eliot cita aquest passatge dels diaris baudelairians cap al final de la darrera part del seu article (1986: 430). 
És evident que Eliot ens presenta l'autor de Les flors del mal tot destacant-ne els aspectes en els quals el sent proper. El mateix que havia fet, val a dir, Carles Riba: quan el I92I li va dedicar el seu article, era encara el poeta del Primer llibre d'estances (1919), ${ }^{23}$ això és: el poeta que mirava consciència endins, que des del primer poema del llibre escrutava la seva ment, i que també se servia d'abstraccions en els seus versos, tal com remarcava de Baudelaire. Eliot, per la seva banda, es mira el món d'una manera semblant a la del poeta francès, en tant que coincideix a lamentar - com hem vist que feia Baudelaire quasi un segle enrere a Mon cour mis à nu— «the disappearance of the idea of Original Sin» (1934: 42), ${ }^{24}$ que és com dir l'absència, en la societat de l'època, d'una actitud ortodoxament cristiana davant la vida (Singh 200I: 84-85):

Through a thorough awareness of the implications of sin Baudelaire raised himself above contemporary dissolution. Eliot also felt deeply the importance of imbuing oneself fully with the implications of sin, and saw in the Church the only means of salvation for human beings trapped in a society bent on mass destruction.

Baudelaire, és clar, no tingué l'emparança de l'Església i el seu dogma. Però Eliot li reconeix, si més no, l'esforç per intentar trobar algun ajust entre l'àmbit humà $i$ l'espiritual, en tant que "what he knew he find out for himself». I és que «one of the unhappy necessities of human existence is that we have to 'find things out for ourselves'». I afegia: «If it were not so, the statement of Dante would, at least for poets, have done once for all» (Eliot 1986: 428).

La raó d'aquesta última afirmació és que Dante havia trobat - i podia oferir als altres poetes - un sistema de pensament, una "filosofia», fonamentada en el cristianisme, a partir de la qual va poder construir una obra com la Divina Comèdia.

\section{DANTE}

Eliot es va ocupar de Dante i de la seva "filosofia» en l'assaig que el 1929 va dedicar al poeta italià, i que fou publicat en forma d'opuscle. ${ }^{25}$ Aquí sorgeix una i poètica.

23. Tot just havia escrit els tres primers poemes del Segon llibre d'estances, encara en plena crisi personal

24. Tot i que al passatge citat Eliot s'està referint a la literatura, sembla clar que la seva apreciació té un abast més ampli. Vegeu Margolis (1972: 167-174).

25. Dante, London, Faber and Faber, 69 p. (1986: 237-277). Encara va publicar dos altres assaigs més breus sobre Dante: un de titulat igualment «Dante» (The Sacred Wood, I920), a tall de ressenya del llibre de Henry Dwight Sedgwick Dante: An Elementary Book for Those who Seek in the Great Poet the Teacher of Spiritual

Caplletra 70 (Primavera, 2021), p. 139-167 
JoRdi MALÉ

Humanisme i critica en T. S. Eliot i Carles Riba

nova coincidència en relació amb Carles Riba, el qual el 1933 també publicava un opuscle sobre l'Alighieri, encara que més breu, amb el títol de Dante $i$ la dona. ${ }^{26}$ La coincidència s'estén a l'admiració que ambdós crítics i poetes sentien per l'autor de la Divina Comèdia: Eliot arribarà a afirmar, el 1950, que «I still [...] regard his poetry as the most persistent and deepest influence upon my own verse» (I985: I25); i Riba, que admetia la influència de Dante en el seu poema «Llàtzer el ressuscitat» d'Esbós de tres oratoris (Guardiola 1993: 183), en una carta al crític Manuel de Montoliu del r6IX-I95I, després d'expressar-li el seu afecte per un poeta com Paul Valéry, li declarava: «Però no és precisament [...] aquell al qual jo més espontàniament recorro quan tinc fam d'una poesia que se m’adigui. Us en citaria abans uns quants. Em limito a dir el primer: Dant» (Guardiola 1991: 524).

Els respectius assaigs sobre l'escriptor florentí són molt diferents perquè ho són les respectives motivacions: el del crític anglès es publicava dins una col-lecció, "The Poets on the Poets», que oferia una sèrie de textos escrits per poetes sobre altres poetes anteriors, «not only for the illumination it throws on the subject it deals with but for the light it reflects on the writers themselves», segons s'explicava en un fullet informatiu (Margolis 1972: 129). L'assaig del crític català, en canvi, és la transcripció d'una conferència donada a Barcelona el 17 de desembre de 1932 per inaugurar la nova «Sala Dante Alighieri» de l'Institut de Cultura i Biblioteca Popular de la Dona.

Com que Riba s’adreçava a un públic majoritàriament femení, i en atenció a la institució que el convidava a la inauguració d'un espai dedicat a Dante, va triar com a tema de la seva conferència el del paper de la dona en la vida i l'obra del poeta. Eliot, per la seva banda, es va centrar en la poesia i va dividir el seu assaig en tres parts: dues sobre la Divina Comèdia (la primera sobre l'Infern i la segona sobre el Purgatori i el Paradís), i la tercera i més breu sobre la Vita Nuova.

Tot i que ambdós assaigs es desenvolupen de manera completament independent, presenten alguns punts de convergència que poden il.lustrar la diferent actitud crítica d'un autor i l'altre.

Tant Riba com Eliot remarquen, per exemple, la mentalitat filosòfica d'un poeta com Dante. Però per motius ben diferents. Per al crític català, l'autor de la Divina Comèdia és «un intel-lectualista que creu que l'home es pot salvar coneixent i distingint el bé i el mal», i sabent "el que és l'home, [...] el que és l'ànima, [...] el que és Déu».

Life (1918); i un de posterior, de 1950, "What Dante means to me» (dins To Criticize the Critic, 1965), dedicat sobretot a explicar, com indica el títol, la influència que el poeta florentí tingué sobre ell.

26. Imprès a Barcelona per l'Institut Gràfic Oliva de Vilanova, de 36 p. (Riba 1988: I06-I23). Anys més tard, Riba va traduir al castellà una biografia francesa del poeta: Louis Gillet, Dante, trad. de Carlos Riba, Barcelona, José Jané Editor, 1947. 
Aquest saber, aquesta ciència, basada en la «fe religiosa», el poeta la "porta, sense rendir-se, a través de l'Infern, del Purgatori, del Paradís, fins als peus de la Santíssima Trinitat» (Riba I988: I08-I09). Una caracterització que serveix a Riba (I988: Io9) per assajar d'explicar per què el poema s'intitula "comèdia»: com que Dante vol tractar del «destí de l'home, el destí de l’ànima», el que fa és

passa[r] en revista la conducta dels homes, de tots els homes movent-se en aquest món visible. I quins quadres li oferia el món visible que el voltava! Als seus ulls, els homes havien de representar una mica de comèdia, havien de semblar més aviat còmics. Dante no podia deixar de veure la desproporció entre el que l'home és per ignorància i el que podria ésser per la ciència».

Eliot, per la seva banda, si es fixa en el component filosòfic de la mentalitat del poeta florentí, és per reprendre un tema que ja havia plantejat a l'article «Dante» publicat el I920: el de la relació entre filosofia i poesia. Aleshores partia d'una afirmació de Paul Valéry: "Parler aujourd'hui de poésie philosophique [...] c'est naïvement confondre des conditions et des applications de l'esprit incompatibles entre elles"» (Eliot 1998: 93). ${ }^{27} \mathrm{El}$ crític anglès posava objeccions a aquesta tesi de Valéry — amb la qual l'autor d'El cementiri mari s'apropava a la idea de la poesia pura - en considerar que "the poet can deal with philosophic ideas, not as matter for argument, but as matter for inspection", i que, consegüentment, "poetry can be penetrated by a philosophic idea» (I998: 95), com és el cas de la Divina Comèdia.

Tenia present el que també apuntava Riba al seu assaig: que Dante va viure «en un moment més aviat intel.lectualista, en un moment en què es tenia una fe absoluta en la ciència, perquè la ciència es basava en una fe religiosa» (Riba I988: I08). Per això Eliot, intentant contrastar la poesia «filosòfica» de Dante amb la d'un poeta llatí com Lucreci, afirma que "Dante had the benefit of a mythology and a theology which had undergone a more complete absorption into life than those of Lucretius»; dit altrament: "The philosophy is an ingredient, it is a part of Dante's world just as it is a part of life» (Eliot 1998: 95).

El que Eliot defensa, davant l'afirmació de Valéry, no és que el poeta hagi de ser filòsof, sinó que pot haver-hi poesia construïda a partir de filosofia, de pensament, de ciència, com s'esdevé en diverses parts de la Divina Comèdia. Per això, a l'assaig de 1929, destacarà que llegint el cant del Purgatori "one learns that a straightforward philosophical statement can be great poetry» (Eliot 1986: 252).

En la defensa d'aquest tipus de poesia coincidia amb Riba. Per bé que novament el context literari de cadascun d'ambdós crítics determina les diferents raons de l'un

27. La citació de Valéry prové, segons indica Eliot, d'Athen๔um, 23-VI-I920. 
JoRdi MALÉ

Humanisme i crítica en T. S. Eliot i Carles Riba

i de l'altre. En el cas de l'autor català, ja des de mitjan anys deu trobava que la poesia catalana es caracteritzava principalment per una tendència al realisme (la percepció de la realitat a través dels sentits) i al sentimentalisme (els sentiments purament personals), unes tendències a les quals intentava reaccionar amb les seves Estances. Per això, es preguntava (Riba 1985: I70): ${ }^{28}$

¿li és lícit al poeta de substreure's de pensar, quedar de banda als radicals problemes de l'esperit, fugir d'agitar-los, de donar-los les mitges solucions que calen per cercar encara? En un mot: ¿és ja lícita la paraula i la música del poeta sense un ressò de filosofia?

S'ho preguntava en ressenyar un llibre de poemes de Ferran Soldevila — l'historiador que, de jove, també fou poeta-, llibre que equiparava amb la poesia floralesca del vuit-cents i que qualificava, precisament, de "pre-dantesc» (1985: 170). Tambél'obra d'un altre jove poeta català, les Vint cançons de Tomàs Garcés, duia Riba a referir-se a la mateixa qüestió, en aquest cas partint de les consideracions que el seu mestre Karl Vossler havia fet en una monografia crítica sobre Leopardi. ${ }^{29}$ Vossler hi distingia entre una poesia de "letteratismo», en què «l'inseguita fantasia e gli immaginari soggettivismi si rifugiano nel vuoto dell'artificio verbale», o bé «la via percorsa da Dante, Goethe, Leopardi», la qual «passa attraverso il purgatorio della scienza ed è più che incomoda: pericolosa» (Vossler 1925: 328-329). No cal dir que aquest tipus de poesia que travessa "el purgatori de la ciència», de la filosofia i el pensament, és la que defensen tant el crític alemany com el seu deixeble, Riba. Per això, davant la primera obra poètica de Garcés, que als seus ulls no passava de ser «un bell idil-li d'expertes melodies jugades en senzills instruments populars", reproduïa (en català) el passatge en què Vossler distingia entre els dos tipus de poesia i formulava el seu desig que el novell poeta triés la del segon camí, «el seguit per Dant, Goethe i Leopardi» (Riba 1985: 3II). ${ }^{30}$

Encara un tercer poeta català que tampoc no acabava d'endinsar-se en aquesta via poètica dugué Riba a reprendre, anys després, la mateixa qüestió. Un poeta religiós, com ho fou Dante: Jacint Verdaguer. ${ }^{31}$ Intentant fer llum sobre la seva personalitat i la seva poesia, el crític català apuntava que a l'autor de Canigóli hauria fet molt de servei «una certa dosi de teologia, no ja de Tubinga, sinó simplement de Vic, afegida als seus extraordinaris dots poètics i al seu eminent fervor de caritat». I afegia (Riba 1986: 157):

28. «Poema de l'amor perdut, per Ferran Soldevila» (1916). Vegeu Malé (1995: 43-57).

29. Karl Vossler, Leopardi, Munic, Musarion Verlag, 1923. En citaré una traducció italiana (Vossler I925). 30. "Vint cançons de Tomàs Garcés» (1923). Vegeu Malé (200I: 50-55).

31. A l'article de 1945 "Centenari de Jacint Verdaguer» (... Més els poemes, 1957). 


\begin{abstract}
No vull dir que per a ésser gran poeta calgui ésser filòsof; però la inquietant constatació és que tots els poetes indiscutibles com a màxims han penetrat profundament i subtilment, amb idees exactes i ben lligades, en llurs emocions i en llurs supremes contemplacions de la vida humana.
\end{abstract}

Per a Riba, aquest «do de penetració intel-lectual» fou, en Verdaguer, «molt feble» (1986: I58). I per això en la seva poesia sovint ofereix síntesis «de visió i de misteri» (els misteris de la fe, de la religió cristiana), en lloc de síntesis «de pensament i de visió», com en Dante, en qui els misteris prèviament "han estat posats davant la seva ment, com davant la del teòleg» (1986: 158).

L'interès d'Eliot per aquesta qüestió —Dante al marge — està relacionat, inversament, amb poetes anglesos l'obra dels quals sí que contenia un component «filosòfic» i de pensament, per bé que no sempre de la mena que hauria volgut el crític anglès. Començant pels poetes del segle XVII anomenats "metafísics», que Eliot contribuí a revalorar i li serviren de referència per escriure The Waste Land. John Donne, per exemple, seria un exemple del que anomenava "poeta intel.lectual», en contrast amb autors del segle xIx com Alfred Tennyson o Robert Browning, que serien "poetes reflexius» («reflective poets»), perquè certament pensaven, però no «sentien» els seus pensaments, a diferència de Donne, per a qui «a thought [...] was an experience; it modified his sensibility» ("The Metaphysical Poets», I92I; 1986: 287). En darrer terme, el que Eliot vol expressar és que un poeta setcentista com Donne tingué la virtut que, les seves idees, "he turn them into poetry, and not merely meditate on them poetically»; o amb altres paraules: "[he was] engaged in the task of trying to find the verbal equivalent for states of mind and feeling» (1986: 288-289).

Entre Donne i Tennyson hi havia els poetes romàntics del tombant del segle XIX, envers els quals Eliot no sentí gaire atracció — com remarcava més amunt. Respecte a Coleridge, per exemple, després d'afirmar que un escriptor no podia ser alhora poeta i filòsof, apuntava que l'autor de Biographia Literaria en seria «the apparent example, but I believe that he was only able to exercise the one activity at the expense of the other» («Shelley and Keats», I933; Eliot 1987: 98-99). I feia la crítica següent a Blake («William Blake», I920; Eliot 1986: 322):

What his genius required, and what it sadly lacked, was a framework of accepted and traditional ideas which would have prevented him from indulging in a philosophy of his own, and concentrated his attention upon the problems of the poet.

Per a Eliot, la feina del poeta no és filosofar poèticament, sinó convertir les idees filosòfiques en poesia. I per aconseguir-ho, considerava més adequat no pas concebre un sistema filosòfic propi, com Blake, sinó partir d'un corpus d'idees i pensament 
JoRdi MALÉ

Humanisme i critica en T. S. Eliot i Carles Riba

ja establert i tradicional. Com va fer Dante, el qual, en concebre la Divina Comèdia, partí de la doctrina catòlica i «had behind him the System of St. Tomas, to which his poem corresponds point to point» (1986: 135$).^{32}$

Encara en relació amb la Divina Comèdia, hi ha un passatge del magne poema dantesc que tant Eliot com Riba es van deturar a comentar: el conegut episodi de Francesca i Paolo, del cinquè cant de l'Infern. ${ }^{33}$ Eliot ja s'havia referit a la història d'aquests amants condemnats a l'Infern dins l'esmentat article sobre Dante que publicà el 1920 a The Sacred Wood. Tot comentant les reflexions sobre la Divina Comèdia fetes per un escriptor anglès del segle xix, Walter Savage Landor, discutia la seva interpretació de l'esmentat episodi, segons la qual a Francesca li suposava un alleujament recordar el moment en què estava amb Paolo: "In the midst of her punishment, Francesca, when she comes to the tenderest part of her story, tells it with complacency and delight" (1998: 97). Eliot considerava que això més aviat era «a false simplification», perquè

the ecstasy [es refereix a l'èxtasi amorós amb Paolo], with the present thrill at the remembrance of it, is a part of the torture. Francesca is neither stupefied nor reformed; she is merely damned; and it is a part of damnation to experience desires that we can no longer gratify. For in Dante's Hell souls are not deadened, as they mostly are in life, they are actually in the greatest torment of which each is capable.

La tesi que vol demostrar el crític anglès en l'article és la coherència de la Divina Comèdia, que implica que, en considerar-ne qualsevol episodi, no tan sols la seva interpretació al-legòrica i la seva intenció didàctica, sinó també la seva significació emocional, «cannot be isolated from the rest of the poem» (96). I per això es mira l'escena entre els dos amants essencialment com una baula més de la cadena de sofriment que enllaça els condemnats de l'Infern dantesc.

Quan torna a referir-se a aquest episodi en l'assaig de 1929, Eliot atenua el seu plantejament. Ara l'objectiu primer és intentar aclarir per què la poesia dantesca resulta «extremely easy to read» (1986: 238). Entre les diverses explicacions, es fixa en la relacionada amb el mètode al-legòric emprat pel poeta, en tant que basat en imatges. I conclou que "Dante's is a visual imagination» (1986: 242-243). De manera que,

32. «Shakespeare and the Stoicism of Seneca» (1927). Respecte a aquesta idea de la conveniència de partir d'una filosofia establerta (i tradicional), vegeu la crítica que en fa Wellek (1988: 306-308)

33. Hi ha un altre episodi que va atreure l'atenció de tots dos crítics: el de l'Ulisses del cant Xxvi també de l'Infern. Eliot li dedica un extens comentari en l'assaig de I929 (I986: 247-250) i ja el destacava el I9I9 a "Tradition and Individual Talent» (1986: 19); Riba, tot i que no s'hi refereix al seu assaig de 1932 (dedicat a les dones de Dante), el té present en diversos dels seus escrits, i hi al-ludeix al v. 28 del poema ix de les Elegies de Bierville (vegeu Malé 2018 i Malé 200I: 60-64). 
malgrat que "we cannot extract the full significance of any part [of Dante's poem] without knowing the whole», com ja havia defensat a l'article de I920, sí que podem arribar si més no a una primera interpretació de moltes de les seves parts gràcies a aquest component visual de la poesia dantesca, que ens permet representar-nos el que el poeta veia en la seva imaginació. Així, "we can understand the first Episode that strikes most readers, that of Paolo and Francesca, enough to be moved by it as much as by any poetry, on the first reading", perquè "we can see and feel the situation of the two lost lovers, though we do not yet understand the meaning which Dante gives it» (1986: 245). Aquest sentit, afegeix, només el comprendrem quan situarem l'episodi "into its place in the whole Comedy», perquè aleshores veurem "how this punishment is related to all other punishments and to purgations and rewards» (I986: 246).

L'atenció que Riba va dedicar a aquest episodi de la Divina Comèdia és d'un signe ben diferent. També li interessa quin és el significat de la història d'aquests amants adúlters i dissortats; però, a la inversa d'Eliot, se centra en el seu sentit independentment de la resta del poema. No és que prescindeixi, és clar, de la posició que ocupa entre els damnats de l'Infern, perquè no oblida que «Dante és un teòleg inflexible» (Riba 1988: I22). Però es fixa en el fet que, mentre la reacció del poeta —en tant que personatge del poema - davant d'altres condemnats, com ara els maliciosos, és d'adreçar-los paraules violentes i grolleres sense "gens de pietat», davant Paolo i Francesca, en canvi, després de sentir el relat d'ella, "cau com un cadàver» commogut de pietat. ${ }^{34}$

Per a Riba, aquesta reacció tan singular està en consonància amb la singularitat de l'escena protagonitzada per Francesca: en comparació amb Beatriu, que no deixa de ser una «abstracció» que «toca sempre, si es vol, un idealisme», Francesca representa «la primera figura moderna» en l'obra de Dante i «està en el centre mateix de la concepció moderna de l'Art» (Riba I988: I22). Cal tenir present que la Divina Comèdia, escrita a principis del segle XIV, malgrat pertànyer a la literatura de l'edat mitjana, de rigorosa i severa religiositat, conté indicis de la transició cap al Renaixement, en què la condició humana passarà a ser el centre de la concepció de l'existència, concepció que engendrarà un nou —i modern— tipus d'art (veg. De Sanctis I958: 283 i n. 2). Per això Riba (I988: I22) es pregunta:

Què hauria pogut ésser mai la novel.la, el drama, si els homes enfoquessin les passions humanes d'una manera estrictament teològica? S'han d'enfocar humanament; s'han d'enfocar així: això que ha passat [en referència als amors de Francesca i Paolo], que teològicament està malament, humanament ha passat.

34. Infern V, v. I39-I42: «Mentre che l'uno spirto [= Francesca] questo dise, / l'altro [= Paolo] piangea, sì che di pietade / io venni men così com'io morisse; / e caddi come corpo morte cade» (Dante I988: 43). 
JoRdi MALÉ

El contrast amb Eliot és evident. No és que el crític anglès sigui aliè a l'emoció que suscita aquest episodi: el seu component emotiu el destacava a l'assaig de 1929, talment com ja ho havia fet el 1919 en esmentar el passatge dantesc dins «Tradition and Individual Talent» (Eliot 1986: 19). Però l'estricte esperit religiós d'Eliot l'apropava més a l'època medieval que no a la renaixentista, i per això el que li interessava era la situació de Francesca i Paolo en l'estructura de damnació de l'infern i dins el conjunt del poema concebut per «the mediaeval mind of Dante» (1990: 60): 35 "When we come to fit the episode into its place in the whole Comedy, and see how this punishment is related to all other punishments and to purgations and rewards, we can appreciate better the subtle psychology [d'alguns dels seus versos]» (I986: 246).

Riba, en canvi, des de l'inici de la seva trajectòria s'havia sentit atret pel Renaixement i l'humanisme italià — com bona part de la seva generació- (veg. Malé 200I: 64-IO2; Malé 1995 i també Gavagnin 2005), i d'aquí ve que destaqui, de l'episodi dels amants condemnats, justament allò que s'escapa de la inflexible interpretació teològica de la mentalitat medieval: perquè, afirma, «la missió del poeta amb els seus personatges, no és jutjar-los, sinó comprendre'ls i fer-nos-els comprendre» (Riba I988: I23). Comprendre'ls, s'entén, en allò que tenen, justament, d'humans. A l'inici del seu assaig, Riba destacava la doble formació de Dante: una "formació teològica dominicana, corregida per una formació més cordial, que era la franciscana», aquesta última caracteritzada, en contrast amb «la raonabilitat una mica eixuta, fins i tot ferotge» de la primera, "per un renovador impuls d'amor» (I988: I08). La Divina Comèdia hauria pogut ser, així, «un de tants, si es vol el millor, dels llibres medievals de poesia eixarreïda, nodrida en la Teologia», però el poeta florentí «en va fer un poema d'amor; i aquest amor va ésser talment la flama que abrandà, sobretot, la convicció de Dante sobre la seva ciència» i, doncs, sobre la seva fe (I988: 108-109).

\section{GOETHE}

Un escriptor que més d'una vegada apareix relacionat amb Dante tant en textos d'Eliot com de Riba és Goethe. L'autor del Faust va suscitar l'interès tant del crític català com de l'anglès, per bé que, com veurem, la veneració que li tingué el primer contrasta amb la consideració més aviat crítica que en feia el segon. Tots dos, al marge d'esmentar-lo en textos diversos, li van dedicar un assaig: Riba escriurà un

35. La citació pertany a l'article «What is a classic?» (I944). Sobre l'atracció d'Eliot per l'edat mitjana, vegeu Frye (1969: 15-18) i Davies (1997: 48-49). 
breu pròleg per a una antologia de textos de l'autor alemany traduïts per diferents escriptors catalans, que va aparèixer el $1932^{36}$ - a més de centrar en la seva figura part de la conferència «Humanisme i poesia» del mateix any, com hem vist—; i Eliot, el farà objecte del parlament que va llegir a la Universitat d'Hamburg («Goethe as the Sage», 1955) arran del lliurament d'un premi (el Hanseatic Goethe Prize de 1954), el text del qual publicarà dins el volum On Poetry and Poets (1957).

Goethe apareix sovint als textos d'Eliot anteriors a l'esmentat parlament, sobretot del període d'entreguerres, on el tracta d'una manera molt més severa i crítica que no l'any 1955. En un de 1933 («Shelley and Keats»), per exemple, tot abordant el tema de la relació entre poesia i filosofia — vegeu l'apartat anterior-, arriba a afirmar que «he dabbled in both philosophy and poetry and made no great success of either» (Eliot 1987: 99).

En l'assaig sobre Dante de 1929, d'altra banda, Goethe li servia de contrast respecte al poeta de la Divina Comèdia per tractar una qüestió que sempre va interessar-lo: la de la relació entre vida i obra, vinculada amb la de les creences de l'home i les del poeta. Ja a «Tradition and Individual Talent» (1919) defensava que l'experiència de la creació literària havia de ser del tot independent de l'experiència vital de la persona que escrivia: «The more perfect the artist, the more completely separate in him will be the man who suffers and the mind which creates» (Eliot 1986: 18). I, de manera conseqüent, a l'assaig de 1929 afirmava que «we can make a distinction between what Dante believes as a poet and what he believed as a man», i que «his private belief becomes a different thing in becoming poetry» (1988: 258). I aleshores establia el contrast entre el poeta italià i l'alemany: «With Goethe [...] I often feel too acutely 'this is what Goethe the man believed', instead of merely entering into a world which Goethe has created», i això provocava a Eliot, com a lector de les obres goethianes, «a strong sentiment of disbelief in what he believes: Dante does not» (I988: 258).

Riba adoptava, respecte a aquesta qüestió, una posició diferent de la del crític anglès. Val a dir que en alguns dels seus primers articles s'apropava al pensament d'Eliot en el sentit que, per exemple, defensava el que en deia la «sinceritat artística» per davant de la "sinceritat moral», això és: la preocupació de l'escriptor no hauria de ser buscar la correspondència entre el que viu i sent i el que expressa (la sinceritat moral), sinó aconseguir de crear, amb els mitjans del seu art, una "realitat literària»

36. "Als joves lectors d'aquest llibre», dins Goethe. Antologia que la Generalitat dedica a les escoles de Catalunya, Barcelona, Generalitat de Catalunya, I932, p. I5-I8 (Riba 1988: I29-I3I). Riba, d'altra banda, dedicarà una part de la seva tesi doctoral sobre la Nausica de Joan Maragall (llegida el 1938) a tractar de Goethe i la seva Nausikaa (1986: I78-2II).

Caplletra 70 (Primavera, 2021), p. 139-167 
JoRdi MALÉ

Humanisme i critica en T. S. Eliot i Carles Riba

diferent $\mathrm{i}$ independent de la real (Riba 1985: III).$^{37}$ Per al jove Riba, com per al jove Eliot, era més important la poesia i l'art que no, per exemple, l'autenticitat de la passió o el sentiment que poguessin originar-los.

Ara: el crític dels Escolis mai no va separar tant vida i obra com va intentar ferho el crític de The Sacred Wood, i la seva devoció per Goethe, per l'autor de Poesia i veritat, hi va contribuir decisivament. Són diversos els textos de Riba, i de diferents èpoques, en què va especular sobre, justament, quina relació guardaven els seus propis poemes (i el conjunt dels seus textos) amb la seva vida, amb l'home que ell era; fins i tot en poemes com ara el titulat «Versos meus d'altre temps» (de 1930, dins el Segon llibre d'estances; Riba 2019: 158): ${ }^{38}$

Fons sense temps dels anys, versos inerts, mirall
on inclino un silenci que fou gest, que voldria
recordar-se i perfer-se - ah mai feliç treball!
Vague d'atzars, em cerco en el triomf d'un dia.

Eliot, en canvi, ben aviat, al ja citat assaig «Tradition and the Individual Talent» (I919), va formular el que anomenava una «Impersonal theory of poetry»: l'important, per al poeta, ha de ser prendre consciència del passat i anar inserint-se dins la tradició; i, per fer-ho, li cal "[a] process of despersonalization», perquè la seva evolució ha de ser «a continual self-sacrifice, a continual extinction of personality» (I986: I8). D'aquí ve la definició de la poesia que donava en aquest assaig primerenc: «Poetry is not a turning loose of emotion, but an escape from emotion; it is not the expression of personality, but an scape of personality» (1986: 2I). Una concepció de la poesia que ha estat considerada com a mostra d'«antihumanism» (Davies 1997: 48). Riba, per contra, ja en un dels seus primers articles es pronunciava en sentit contrari, amb l'aval de l'autor del Werther: "Goethe, a les seves velleses, aconsellava als poetes joves de no emprendre poemes llargs. Posava ell l'obra del poeta com un dietari lliure, ininterromput, d'emocions» (Riba 1985: 170). Perquè l'obra de l'autor alemany —com dirà al pròleg que li dedicarà el 1932 ("Als joves lectors d'aquest llibre») — fou «l'expressió natural, immediata i clara» de la seva vida (Riba 1988: 130).

Riba no desmentirà, al llarg de la seva trajectòria crítica, aquesta relació entre vida i obra, per bé que no deixarà mai de reflexionar-hi i especular-hi. Eliot, per la seva banda, en textos més de maduresa, matisarà la seva teoria de la impersonalitat poètica. Fins a establir —a la conferència «Yeats» de 1940—, que n'hi havia de dos tipus: la

37. "Cellini» (1919). Veg. Malé (1995: 97-109 i I66-192).

38. Sobre aquest punt de l'ideari literari de Riba, vegeu Malé (200I: 197-232). 
que és «natural to the mere skilful craftsman» i la que és «more and more achieved by the maturing artist». I precisarà sobre aquesta última: «The second impersonality is that of the poet who, out of intense and personal experience, is able to express a general truth; retaining all the particularity of his experience, to make of it a general symbol» (I990: 255). ${ }^{39}$

Aquesta qualitat d'expressar «a general truth» a partir de l'experiència pròpia, Eliot l'atribueix només a poetes arribats a la maduresa, com en el cas de Yeats. I és també una qualitat que hi està relacionada i també només assolible amb el pas dels anys, la que atribuirà — quan ell mateix ja serà un crític més madur — a Goethe: la saviesa, que definia amb aquests termes: "Wisdom is a native gift on intuition, ripened and given application by experience, for understanding the nature of things, certainly of living things, most certainly of the human heart» (I990: 22I). Goethe fou, en aquest sentit, un savi («Goethe as the Sage», 1955):

The wise man $[\ldots]$ is one whose wisdom springs from spiritual sources, who has profited by experience to arrive at understanding, and who has acquired the charity that comes from understanding human beings in all their variety of temperament, character and circumstance.

Eliot vincula la saviesa amb la comprensió del que és «humà», del cor de l'home i el seu caràcter divers. Una idea que de ben segur hauria compartit Riba, que en el seu pròleg de 1932 («Als joves lectors d'aquest llibre») afirmava (Riba I988: I30):

Potser no ha existit un altre home tan humanament complet com ell. Hi hagué en ell les forces, les qualitats, les tendències, les maneres més contradictòries; tant en la part moral com en la intel-lectual. Tot allò que els homes solen ésser o tenir per separat, Goethe ho reuní ell sol amb una intensitat no superada.

És evident que a Riba li interessa, en aquest text adreçat als joves, presentar la vida i l'obra de Goethe com a exemplars i com a models, no pas a imitar sinó a conèixer i a estudiar, per «extreure['n] els principis vivents, perennes, i, partint-ne, seguir endavant, cap a una major perfecció de cada home i de tots» (Riba 1988: I30). En aquesta darrera apreciació, Eliot difícilment hi hauria convingut, ja que Goethe era un autor a qui respectava i potser fins admirava, però que no sembla que li agradés gaire. ${ }^{40}$

39. Sobre aquesta qüestió en Eliot, vegeu Wellek i988: 299-310.

40. En aquest sentit, l'assaig que li dedica el I955, motivat pel parlament llegit en una universitat alemanya arran d'un premi que duu el nom de Goethe, fa una mica l'efecte d'un exercici de diplomàcia. Fins al punt que Eliot no pot deixar d'esmentar, per mirar de justificar-la, la crítica feta a l'article «Shelley and Keats» (I933) en què

Caplletra 70 (Primavera, 2021), p. 139-167 
El fet de qualificar-lo de «savi», en qualsevol cas, per a Eliot implicava encara una altra qualitat: «I believe [...] that it is finally by virtue of the wisdom informing his work, that an author enters this category of 'great Europeans'» (I990: 22I). I amb aquesta qualitat, hi anaven aparellats dos atributs: «Permanence and Universality» (I990: 2II), que són característics dels clàssics. Riba no hi hauria posat cap objecció.

\section{A TALL DE CONCLUSIÓ: CULTURA I HUMANISME}

Si fos Riba qui hagués fet la caracterització de Goethe com a savi i «gran europeu», amb les qualitats de permanència i universalitat, l'hauria associat directament al concepte d'humanisme. Si l'Eliot que l'hagués feta fos el jove del tombant dels anys vint, hauria anat a parar al concepte de tradició, dins el qual es diluïa el «talent individual» i, doncs, la personalitat de l'autor (veg. «Tradition and Individual Talent», 1919) —en el que se n'ha dit, com apuntava més amunt, «antihumanisme». Aquest primer Eliot, que impulsaria els postulats del New Criticism, divergeix completament del Riba que, sobretot als anys deu i vint, practicarà una crítica de mena idealista, amb De Sanctis i Vossler com a referents, en la qual la personalitat creadora té un paper destacat.

L'Eliot més madur, en canvi, és el que vincularia Goethe amb el concepte de cultura, en el qual — com hem vist - fonamentava la seva concepció de l'humanisme; cultura en el sentit de civilització (Eliot 1954: 13). ${ }^{41}$

No n'hauria pas discrepat, Riba, d'aquesta vinculació. Com tampoc del fet que Eliot es referís sobretot a la noció de "cultura europea». Ara: per a aquest Eliot, el de després de la conversió a l'anglicanisme, la «dominant force» que havia creat aquesta cultura era la religió: «the common tradition of Christianity which has made Europe what it is», amb «the common cultural elements which this common Christianity has brought with it» (1954: I22). No s'oblidava pas dels clàssics grecollatins, però els filtrava a través de la tradició del cristianisme: «The Western world has its unity in this heri-

afirmava que l'autor alemany havia passat el temps entretingut tant en la filosofia com en la poesia sense reeixir en cap d'ambdues («he dabbled in both philosophy and poetry and made no great success of either», citat supra). 4I. Eliot dedicarà tot un llibre al concepte de cultura: Notes towards the Definition of Culture (I948) —d'on prové la darrera referència-, del qual difícilment se'n pot extreure una definició precisa. Thomas J. Diehl, en la seva tesi sobre Eliot de 1947, en proposava una: «In Eliot's mind culture is an attitude of mind, conditioned by philosophy and religion, which enables man to recognize and impels him to choose, whatever is good, true, and beautiful» (1947: 42); però resulta dubtosa perquè, per exemple, no cita cap text d'Eliot en què apareguin els tres darrers conceptes de la definició. 
tage, in Christianity and in the ancient civilisations of Greece, Rome and Israel, from which, owing to two thousand years of Christianity, we trace our descent» (I954: I23).

Mentre Eliot pensa en la cultura europea com a cultura cristiana, Riba, sense refusar el component cristià de la tradició occidental, en parla sobretot com a «cultura humanística» (1985: 317; «Una generació sense novel-la», I925), l'arrel de la qual són els clàssics grecollatins, i sobretot els grecs, de qui creu que encara és vàlida la força educativa i civilitzadora.

Dues posicions crítiques diferents davant una mateixa cultura, de la qual tots dos van ser insignes representants.

\author{
JORDI MALÉ \\ Universitat de Lleida \\ jordi.male@udl.cat \\ ORCID 0000000310970708
}

\title{
REFERÈNCIES BIBLIOGRÀFIQUES
}

Alighieri, Dante (1988) La Divina Commedia. Testo critico della Società Dantesca Italiana, reveduto, col commento scartazziniano rifatto da Giuseppe Vandelli, Milano, Ulrico Hoepli Ed. [2I ed.]

Baвbitt, I. (1908) «What Is Humanism?», dins Literature and the American College, Boston, Houghton Mifflin, I908, p. I-3I. [<http://www.nhinet.org/lacr.htm>, consulta: 06-OI-2020.]

Baudelaire, Ch. (1975) Euvres complètes, vol. i, a cura de C. Pichois, Paris, Gallimard. Davies, T. (1997) Humanism, London \& New York, Routledge.

De Sanctis, F. (1958) Storia della letteratura italiana, a cura de Niccolò Gallo, Torino, Einaudi. [1870-I87I, Ia ed.]

Dienl, T. J. (1947) The Idea of Humanism According to T. S. Eliot. Master's Theses, Paper 137. [<http://ecommons.luc.edu/luc_theses/I37>, consulta: 05-OI-2020.]

Eliot, T. S. (1930) «Religion without Humanism», dins Norman Foerster (ed.), Humanism and America: Essays on the Outlook of Modern Civilisation, New York, Farrar and Rineheart, p. IO5-II2.

- (1934) After Strange Gods: a Primer of Modern Heresy, London, Faber and Faber.

— (1954) Notes towards the Definition of Culture, London, Faber and Faber. [1948, ra ed.]

- (1970) For Lancelot Andrewes, London, Faber and Faber. [1928, Ia ed.]

— (1985) To Criticize the Critic, London, Faber and Faber. [1965, Ia ed.]

Caplletra 70 (Primavera, 2021), p. 139-167 
JoRdi MALÉ

Humanisme i critica en T. S. Eliot i Carles Riba

- (1986) Selected Essays, London, Faber and Faber. [1951, 3a ed.]

- (1987) The Use of Poetry and the Use of Criticism, London, Faber and Faber. [1933, Ia ed.]

— (1990) On Poetry and Poets, London, Faber and Faber. [1957, ra ed.]

- (1998) The Sacred Wood and Major Early Essays, Mineola, New York, Dover Publications. [i920, Ia ed.]

Frye, N. (1969) T. S. Eliot, trad. cast. de J. Díaz, Madrid, E. P. E. S. A.

Gavagnin, G. (2005) Classicisme i Renaixement: una idea d'Itàlia durant el Noucentisme, Barcelona, Publicacions de l'Abadia de Montserrat.

Guardiola, C.-J., ed. (1991) Cartes de Carles Riba II: 1939-I952, Barcelona, Edicions de la Magrana.

- (1993) Cartes de Carles Riba III: 1953-1959, Barcelona, Edicions de la Magrana.

JaEger, W. (I92I) Humanismus und Jugendbildung, Berlin, Weidmannsche Buchhandlung.

- (1988) Paideia: los ideales de la cultura griega, trad. de J. Xirau i W. Roces, Madrid, Fondo de Cultura Económica. [1936, ra ed.]

Malé, J. (1995) Carles Riba i el Noucentisme. Les idees literàries (I9I3-I920), Barcelona, Edicions de la Magrana.

- (200I) Poètica de Carles Riba. Els anys del postsimbolisme 1920-1938, Barcelona, Edicions de la Magrana.

- (2003) «L'humanisme ribià com a principi educatiu i de construcció nacional», dins R. Cabré, M. Jufresa i J. Malé, Polis i nació. Politica i literatura (I900-I939), Annexos 2 d'Ítaca. Quaderns Catalans de Cultura Clàssica, Barcelona, Institut d'Estudis Catalans, 2003, p. I43-I63.

- (2018) «Una odissea transtextual: els Ulisses de Carles Riba», dins C. Gregori i R. X. Rosselló (ed.), L'empremta del mite en la literatura del primer terç del segle XX, Barcelona, Publicacions de l'Abadia de Montserrat, 20I8, p. 79-IIO.

Margolis, J. D. (1972) T. S. Eliot's intellectual development 1922-1939, Chicago \& London, The University of Chicago Press.

Medina, J. (1989) Carles Riba (I893-1959), 2 vol., Barcelona, Publicacions de l'Abadia de Montserrat.

Miralles, C. (2007) Sobre Riba, Barcelona, Proa.

Nicolau d'Olwer, Ll. (1933) «De l'humanisme», Universitat Catalana, 8, febrer, p. I. Pavan, M. (1977) Antichità classica e pensiero moderno, Firenze, La Nuova Italia.

Riba, C. (1985) Obres Completes II, Crítica I, a cura d'Enric Sullà, Barcelona, Edicions 62.

- (1986) Obres Completes III, Crítica 2, a cura d'Enric Sullà i Jaume Medina, Barcelona, Edicions 62. 
JORDI MALÉ

Humanisme i critica en T. S. Eliot i Carles Riba

- (1988) Obres Completes IV, Crítica 3, a cura d'Enric Sullà i Jaume Medina, Barcelona, Edicions 62.

- (2019) Llibres de poesia. Amb tots els comentaris del poeta, a cura de Jordi Malé, Barcelona, Edicions 62.

Singh, N. K. (200I) T. S. Eliot. A Reconsideration, New Delhi, A.P.H. Publishing Corporation.

Vossler, K. (1925), Leopardi, trad. it. de Tomaso Gnoli, Napoli, Riccardo Ricciardi editore. [1923, Ia ed.]

Wellek, R. (1988) Historia de la crítica moderna (I750-1950), trad. de F. Collar SuárezInclán, Madrid, Gredos. [1986, Ia ed.]

Worthen, J. (20I7) T. S. Eliot. Una breu biografia, trad. d'Iñaki Tofiño, [Pals], L'Art de la Memòria Edicions. 